\title{
Pengaruh Kepuasan Komunikasi terhadap Motivasi Kerja Karyawan pada PD BPR Bank Pasar Bogor
}

\author{
Effect of Communication Satisfication on Employee Motivation in PD BPR Bank Pasar Bogor
}

Taufiq Azhary Siregar ${ }^{*}$, Aida Vitayala S Hubeis ${ }^{2 \ddagger}$, dan Nurmala Katrina Pandjaitan ${ }^{2 *}$

1) Magister Manajemen dan Bisnis IPB

Jl. Raya Pajajaran, Kampus IPB Gunung Gede, Bogor

2) Departemen Komunikasi dan Pengembangan Masyarakat, Fakultas Ekologi Manusia, Institut Pertanian Bogor "Jl. Kamper, Kampus IPB Darmaga Bogor 16680

\begin{abstract}
ABSTRAK
Komunikasi adalah sarana mengadakan koordinasi antara berbagai subsistem dalam organisasi. Kepuasan komunikasi pegawai yang tinggi secara perorangan akan mendorong kinerja sumber daya manusia secara keseluruhan dan memberikan feedback tepat terhadap perubahan perilaku, yang direfleksikan dalam kenaikan produktifitas. Tahun 2013 terjadi banyak penutupan BPR (Bank Perkreditan Rakyat) di berbagai daerah, yaitu sembilan BPR salah satunya berada di daerah kota Bogor. Penelitian ini meneliti pengaruh kepuasan komunikasi terhadap motivasi kerja karyawan. Obyek penelitian yang diambil adalah semua karyawan PD BPR Bank Pasar Bogor. Metode yang dipakai dalam penelitian ini adalah metode survei, dengan total responden 43 orang. Metode pengolahan data menggunakan analisis deskriptif dan statistik Partial Least Square (PLS) dengan SmartPLS 2.0. Berdasarkan hasil analisis didapat kepuasan komunikasi berpengaruh terhadap motivasi kerja karyawan, nilai R-square 0,6121 bermakna bahwa peubah bebas (kepuasan komunikasi) mampu menerangkan keragaman peubah terikat (motivasi) 61,21\%, disamping pengaruh nyata kepuasan komunikasi terhadap motivasi kerja.
\end{abstract}

Kata kunci: karyawan, kepuasan komunikasi, motivasi kerja

\begin{abstract}
ABSTRACK
Communication is organized coordination between various subsystems within the organization. High employee communication satisfaction individually will drive the performance of human resources as a whole and provide the right feedback on behavior change, which is reflected in the increase in productivity. In 2013 the closing happened many BPR in various areas, namely ninth BPR, one of which is in the city of bogor. This study examined the influence of communication satisfaction regarding how to employee motivation. The object of the research taken are all employees in PD BPR Bank Pasar Bogor Bogor. The methods used in this study using the method of survey which the total number of respondents there were 43 peoples. Method of processing data using descriptive and statistical analysis using Partial Least Squares (PLS) using SmartPLS 2.0. Based on theresults of the analysis satisfaction of communication influence on employee motivation, the value of R-square on the research is 0.6121 percent, which means that the exsogen variable (satisfaction of communication) are able to explain the diversity of the endogen variable (motivation) by $61.21 \%$, also significant effects between variable communication satisfaction of work motivation.
\end{abstract}

Key words: communication satisfaction, employee, work motivation

\footnotetext{
*) Korespondensi:

Jl. Taman Malabar No. 15 Kota Bogor 16151; e-mail: taufiq.azhary@gmail.com
} 


\section{PENDAHULUAN}

Suatu organisasi, khususnya perkantoran, melakukan kegiatan komunikasi. Komunikasi merupakan sarana mengadakan koordinasi antara berbagai sub sistem dalam perkantoran (Primadini, 2012). Suatu perkantoran berfungsi baik, ditandai oleh adanya kerjasama secara sinergik dan harmonis dari berbagai komponen yang dikonstruksi dan dipelihara dengan komunikasi baik. Artinya, ketika proses komunikasi antar komponen tersebut dapat diselenggarakan secara harmonis, maka organisasi tersebut semakin kokoh dan kinerja organisasi akan meningkat dan bertumbuh, serta terjaga. Komunikasi dapat memelihara motivasi dengan memberikan penjelasan kepada para pegawai tentang apa yang harus dilakukan, seberapa baik mengerjakannya dan apa yang dapat dilakukan (Khoerunnisa, 2013). Salah satu faktor yang menumbuhkan motivasi karyawan antara lain lingkungan kerja kondusif dan hubungan komunikasi harmonis antar karyawan yang bekerja dalam suatu organisasi (Saepulloh, 2004).

Aktivitas komunikasi di perkantoran senantiasa disertai dengan tujuan yang ingin dicapai. Budaya komunikasi dalam konteks komunikasi organisasi harus dilihat dari berbagai sisi (Mangkuprawira dan Hubies, 2007). Sisi pertama adalah komunikasi antara atasan kepada bawahan, sedangkan sisi kedua adalah antara pegawai yang satu dengan pegawai yang lain. Sisi ketiga adalah antara pegawai kepada atasan. Masing-masing komunikasi tersebut mempunyai pola masing-masing. Di antara kedua belah pihak harus ada two-way-communications atau komunikasi dua arah, yang biasa disebut komunikasi timbal balik. maka diperlukan adanya kerjasama yang diharapkan untuk mencapai cita-cita, baik cita-cita pribadi maupun kelompok guna mencapai tujuan suatu organisasi.

Komunikasi merupakan sarana untuk mengadakan koordinasi antara berbagai sub sistem dalam perkantoran. Terdapat dua model komunikasi dalam rangka meningkatkan kinerja dan mencapai tujuan perkantoran. Pertama adalah komunikasi koordinatif, yaitu proses komunikasi yang berfungsi untuk menyatukan bagian-bagian (sub sistem) perkantoran. Kedua adalah komunikasi interaktif, yaitu proses pertukaran informasi yang berjalan secara berkesinambungan, pertukaran pendapat dan sikap yang dipakai sebagai dasar penyesuaian di antara sub-sub sistem dalam perkantoran, maupun antara perkantoran dengan mitra kerja (Primadini, 2012). Frekuensi dan intensitas komunikasi yang dilakukan juga turut memengaruhi hasil dari suatu proses komunikasi tersebut.

Komunikasi yang terjadi antar pegawai dan kompetensi komunikasi yang baik akan mampu memperoleh dan mengembangkan tugas yang diemban oleh pegawai, sehingga tingkat kinerja suatu organisasi (perkantoran) menjadi semakin baik. Begitu pula sebaliknya, apabila terjadi komunikasi yang buruk akibat tidak terjalinnya hubungan baik, sikap yang otoriter atau acuh, perbedaan pendapat atau konflik berkepanjangan, dan sebagainya. Hal tersebut dapat berdampak pada hasil kerja yang tidak maksimal. Terdapat unsur komunikasi yang penting dalam melakukan komunikasi, contohnya seperti pengirim, pendengar dan pesan (Mangkuprawira dan Hubies, 2007). Komunikasi juga mengalami hambatan seperti persepsi pesan yang berbedabeda, terjemahan pesan yang salah dan tidak ada umpan balik. Hal-hal seperti ini penting untuk di perhatikan, ketika berkomunikasi agar tujuannya dapat tercapai. Beberapa penelitian menyatakan bahwa kepuasan komunikasi akan berpengaruh terhadap kinerja (Winska, 2010; Tuzun, 2013, Ekaningsih, 2013; Purwanto, 2013; Aisah, 2011; Untung dan Agus, 2010; Wahyuni, 2009; dan Arifin, 2005). Kepuasan komunikasi ini diukur dari beberapa faktor, yaitu iklim komunikasi, kepuasan komunikasi terhadap pengawas, integrasi organisasi, informasi perusahaan mutu media komunikasi, komunikasi dengan rekan kerja, umpan balik individu, dan komunikasi atasan dengan bawahan (Down dan Hazen, 1977).

Kepuasan komunikasi pegawai yang tinggi secara perorangan akan mendorong kinerja sumber daya manusia (SDM) secara keseluruhan dan memberikan feedback tepat terhadap perubahan perilaku, yang direkflesikan dalam kenaikan produktivitas. Salah satu organisasi yang bergerak di bidang jasa adalah Bank. Berdasarkan UndangUndang No. 7 Tahun 1992 tentang perbankan sebagaimana telah diubah dengan Undang-Undang Nomor 10 Tahun 1998, bank adalah badan usaha yang menghimpun dana dari masyarakat dalam bentuk simpanan dan menyalurkannya kepada masyarakat dalam bentuk kredit/bentuk-bentuk lainnya dalam rangka meningkatkan taraf hidup rakyat banyak. Berdasarkan jenisnya, bank terdiri dari dua, yaitu Bank Umum dan Bank Perkreditan Rakyat (BPR). 
Bank umum adalah bank yang melaksanakan kegiatan usaha secara konvensional dan atau berdasarkan prinsip syariah yang dalam kegiatannya memberikan jasa dalam lalu lintas pembayaran. BPR adalah bank yang melaksanakan kegiatan usaha secara konvensional dan berdasarkan prinsip syariah yang dalam kegiatannya tidak memberikan jasa dalam lalu lintas pembayaran. Bentuk hukum bank umum dan BPR dapat berupa Perseroan Terbatas, Perusahaan Daerah dan Koperasi. Tujuan dari BPR, antara lain menunjang pelaksanaan pembangunan nasional dalam rangka meningkatkan pemerataan, pertumbuhan ekonomi dan stabilitas nasional ke arah peningkatan kesejahteraan rakyat banyak.

BPR dapat diartikan sebagai salah satu jenis bank yang dikenal melayani golongan pengusaha mikro, kecil dan menengah. Pada umumnya dan lokasi yang ditempati berdekatan dengan tempat masyarakat yang membutuhkan. Fungsi BPR tidak hanya menyalurkan kredit kepada para pengusaha mikro, kecil dan menengah, tetapi juga menerima simpanan dari masyarakat. Penyaluran kredit kepada masyarakat menggunakan prinsip $3 \mathrm{~T}$, yaitu Tepat Waktu, Tepat Jumlah dan Tepat Sasaran, karena proses kreditnya yang relatif cepat, persyaratan lebih sederhana, dan sangat mengerti akan kebutuhan nasabah (BI, 2015). Tahun 2013 terjadi banyak penutupan BPR di berbagai daerah, yaitu 9 dari beberapa BPR yang ada di Indonesia. Penutupan BPR tersebut mengindikasikan adanya permasalahan di dalamnya dimana salah satunya adalah permasalahan ketidaklancaran komunikasi antar pegawai BPR dengan kreditur, sehingga menyebabkan terjadinya kredit macet (Wahyuntoro, 2012). Hasil penelitian Wahyuntoro (2012) menyatakan bahwa terdapat dua faktor yang menyebabkan kredit macet yaitu faktor eksternal, seperti adanya salah urus pengelolaan usaha, masalah keluarga (misalnya perceraian, kematian, sakit berkepanjangan, pemborosan salah satu atau beberapa anggota keluarga debitur), kesulitan likuidasi keuangan, kejadian di luar kekuasaan debitur (misalnya, perang atau bencana alam), dan watak buruk debitur. Faktor internal, berupa faktor penyebab yang berasal dari pihak bank itu sendiri, seperti keteledoran bank mematuhi peraturan pemberian kredit, terlalu mudah memberikan kredit, kurang memadainya jumlah staf yang berpengalaman, lemahnya pengawasan pimpinan kepada staf bagian kredit, jumlah pemberian kredit yang melampaui batas kemam- puan bank dan lemahnya bank mendeteksi kemungkinan timbulnya kredit bermasalah.

Pengukuran kinerja keuangan triwulan ke-3 BPR se-kota Bogor yang dilakukan oleh peneliti dengan menggunakan metode DEA (Data Envelopment Analysis) menunjukkan bahwa efisiensi kinerja keuangan PD BPR Bank Pasar Bogor 96\% menunjukkan kinerja keuangan Bank yang belum efisien, efisiensi maksimal kinerja dengan menggunakan metode DEA 100\% (Ramanathan, 2003). Hal ini menginformasikan bahwa Bank dengan penyaluran kredit besar belum tentu mendapatkan pendapatan besar. Suatu organisasi akan melakukan kegiatan berkomunikasi, apabila komunikasi organisasi berjalan dengan baik, maka hal-hal yang tidak diinginkan seperti kredit macet akan dapat terhindari. Selain itu efek dari komunikasi organisasi yang baik akan menciptakan motivasi yang baik, serta akan meningkatkan kinerja. Komunikasi organisasi berpengaruh terhadap kinerja karyawan di dalam suatu organisasi (Wahyuni, 2009). Hal ini yang membuat tertarik meneliti pengaruh kepuasan komunikasi terhadap motivasi kerja karyawan BPR, khususnya wilayah Bogor, yaitu pada PD BPR Bank Pasar Bogor. BPR tersebut dipilih, karena memiliki angka penyaluran kredit tinggi daripada semua BPR yang ada di kota Bogor, yaitu Rp56.546.900.000 pada Tahun 2013. Kepuasan komunikasi karyawan pada BPR tersebut sangat penting guna mencegah kredit macet, sebab kepuasan komunikasi merupakan hal yang sangat penting dalam proses ber-organisasi dan produktivitas kerja karyawan. Tujuan penelitian adalah menganalisis pengaruh kepuasan komunikasi terhadap motivasi kerja karyawan PD BPR Bank Pasar Bogor.

\section{METODE PENELITIAN}

Penelitian dilakukan di PD BPR Bank Pasar Bogor, kota Bogor, Jawa Barat. Pengumpulan data dilakukan pada bulan Maret 2014. Data dikumpulkan dengan menggunakan kuesioner kepuasan komunikasi, acuan dari CSQ (Communication Satisfaction Questionnaire) oleh Downs C W \& Hazen M (1977) yang diterjemahkan dalam bahasa Indonesia dan kuesioner motivasi berdasarkan teori McClelland's (McClelland's Needs Assessment) diadaptasi dari Steers $\mathrm{R}$ dan Braunstein (1976) yang diterjemahkan dalam bahasa Indonesia. 
Penelitian ini menggunakan pendekatan kualitatif dan kuantitatif. Pendekatan kualitatif, yaitu mendapatkan informasi dengan wawancara, sedangkan pendekatan kuantitatif, menggunakan kuesioner untuk mendapatkan data penelitian. Selain itu penelitian ini dilakukan setelah dilakukan survey pendahuluan tentang pengukuran kinerja keuangan BPR yang ada di kota Bogor dengan menggunakan DEA.

Penelitian ini menggunakan beberapa jenis data berasal dari berbagai sumber yang mencakup data primer, yaitu hasil jawaban kuesioner tentang kepuasan komunikasi dan motivasi, data sekunder, yaitu laporan tahunan, keuangan dan lain-lain. Metode pengumpulan data dalam penelitian ini adalah metode sensus dengan menggunakan daftar pertanyaan (kuesioner) yang data kepada responden. Data untuk mengumpulkan data primer menguji persepsi, sikap dan perilaku responden terhadap kepuasan komunikasi dalam memengaruhi motivasi kerja karyawan PD BPR Bank Pasar Bogor.

Kuesioner berisi pertanyaan-pertanyaan tertutup dan terbuka. Jenis skala yang digunakan baik peubah eksogen dan endogen adalah skala ordinal. Pernyataan-pernyataan dalam bagian ini dibuat dengan menggunakan skala Likert (Umar, 2005) yaitu skala ordinal di mana pada peubah eksogen dapat disimbolkan 1=sangat tidak puas, 2=tidak puas, 3=puas dan 4=sangat puas, sedangkan pada peubah endogen dapat disimbolkan $1=$ sangat tidak setuju, $2=$ tidak setuju, $3=$ setuju dan $4=$ sangat setuju.

Responden yang terlibat dalam penelitian ini adalah seluruh karyawan PD BPR Bank Pasar Bogor yang berada di kantor pusat Bogor Kota Bogor, yaitu 43 karyawan. Status kepegawaian para responden terbagi menjadi dua, yaitu pegawai tetap 27 orang dan pegawai kontrak 16 orang. Berdasarkan strata manajerial perusahaan, bagian Direksi dua orang, Kepala Bagian 4 orang dan bagian Staff 37 orang.

Analisis pengaruh kepuasan komunikasi terhadap motivasi kerja karyawan pada PD BPR Bank Pasar Bogor menggunakan teknik analisis
SEM (structural equation modeling) dengan metode alternatif berbasis variance atau component base SEM yang disebut partial least square (PLS) dengan software smartPLS versi 2.0. Metode PLS menurut Ghozali (2008) mempunyai keunggulan tersendiri, diantaranya data tidak harus berdistribusi normal multivariate (indikator dengan skala kategori, ordinal, interval sampai rasio dapat digunakan pada model yang sama), ukuran contoh tidak harus besar dan model tidak harus didukung dengan teori yang kuat seperti halnya SEM berbasis covariance yang diwakili oleh software AMOS dan LISREL. Model awal pada proyek PLS terdiri dari dua peubah, yaitu peubah eksogen (kepuasan komunikasi) dan peubah endogen (motivasi), dimana peubah kepuasan komunikasi (eksogen) terdiri dari 26 indikator dan peubah (endogen) motivasi terdiri dari 15 indikator. Model awal PLS yang digunakan dalam penelitian disajikan pada Gambar 1.

\section{HASIL DAN PEMBAHASAN}

\section{Evaluasi (Pengujian) Indikator Reflektif (Outer Model)}

Pengujian kelayakan model dilakukan terhadap outer model-reflektif, yaitu pada indikator pembentuk kepuasan komunikasi dan motivasi. Evaluasi model pengukuran hubungan konstruk dengan indikatornya yang bersifat reflektif meliputi pemeriksaan convergent validity, discriminant validity dan composite reliability. Menurut Ghozaly dan Latan (2012), evaluasi outer model-reflektif dilakukan berdasarkan tiga kriteria, yaitu convergent validity, discriminant validity, dan composite reliability. Terdapat dua kriteria dalam pengujian kelayakan inner model menurut Ghozaly dan Latan (2012), yaitu berdasarkan R-square pada konstruk untuk mengidentifikasi kategori model dan path coefisient untuk pengujian hipotesis. Evaluasi indikator pada setiap konstruk dilakukan dengan tiga kriteria yang telah disebutka. Kriteria dan standarisasi evaluasi outer model dapat dilihat pada Tabel 1.

Tabel 1. Kriteria outer model reflektif

\begin{tabular}{|c|c|c|}
\hline Kriteria & Standar & Keterangan \\
\hline Convergent Validity & Loading factor $>0,5$ & $\begin{array}{l}\text { Menilai kekuatan indikator dalam merefleksikan konstruk } \\
\text { laten Chin dalam Pujiwati (2012) menyatakan, jika nilai } \\
\text { loading }<0,5 \text { maka indikator harus didrop }\end{array}$ \\
\hline Discriminant Validity & AVE $>0,5$ & Mengukur ketepatan model refleksi \\
\hline Composite Reliability & Reliabilitas komposit $>0,6$ & Kestabilan dan konsistensi internal indikator yang baik \\
\hline
\end{tabular}

Sumber: Pujiwati, 2012 


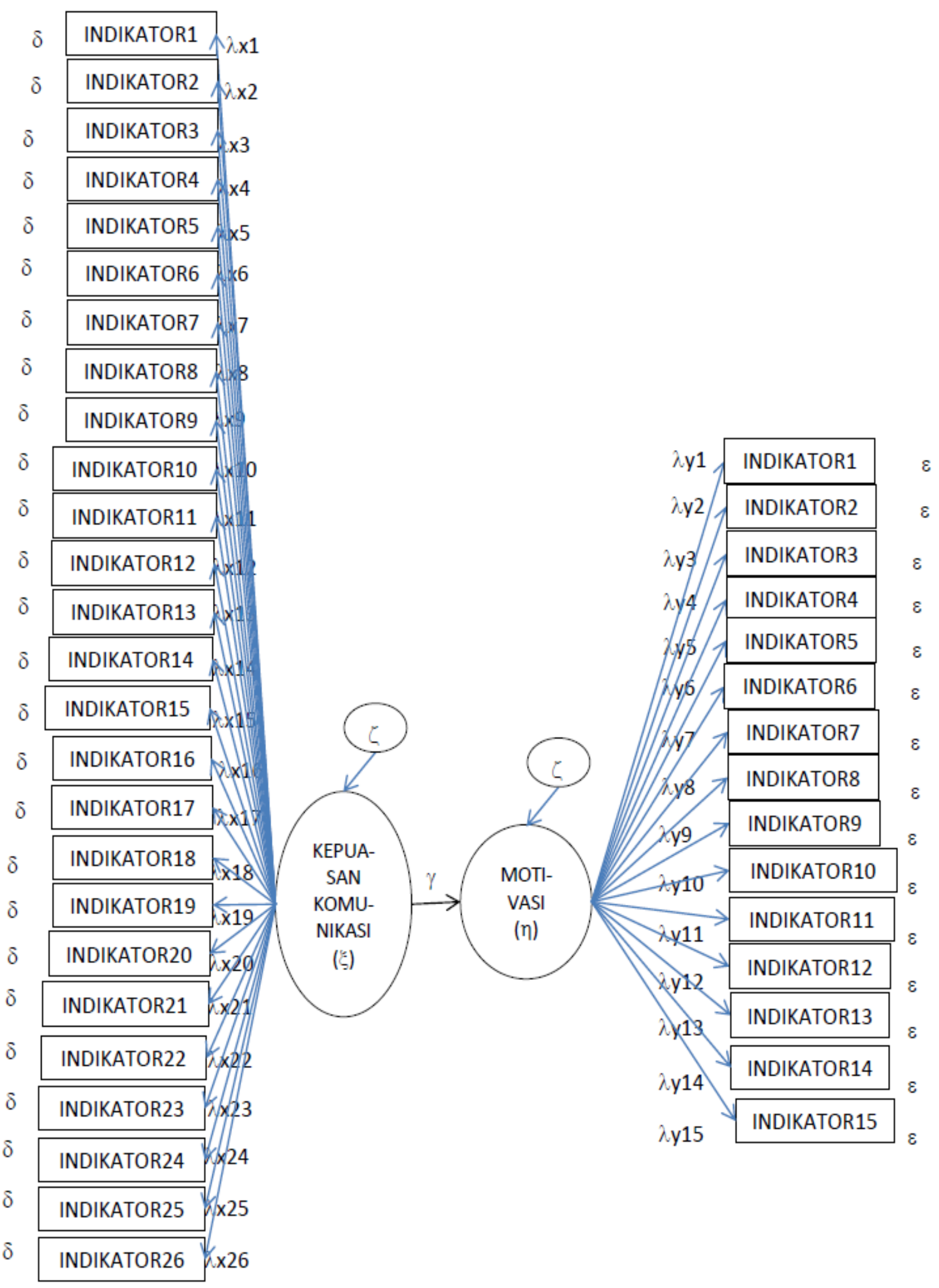

Gambar 1. Model awal PLS 


\section{Convergent Validity (Reliabilitas Indikator)}

Reliabilitas indikator dicerminkan dari nilai loading factor yang merefleksikan kekuatan interelasi antara konstruk dengan indikatorindikatornya. Pada Gambar 2 dapat dilihat bahwa indikator pembentuk konstruk kepuasan komunikasi dan motivasi terbentuk secara reflektif. Nilai loading yang terbentuk semuanya harus lebih dari 0,5, apabila kurang dari 0,5, maka indikator harus didrop atau dikeluarkan agar dilakukan menghasilkan model yang baru setelah pemeriksaan loading faktor yang sesuai dengan kriteria. Model yang baru ini akan dilakukan perhitungan/ evaluasi discriminant validity, dan composite reliability menurut kriteria yang ditentukan sebelumnya. Nilai convergent validity digunakan untuk mengukur tingkat refleksi intererasi indikator terhadap konstruk.

Berdasarkan Tabel 2 terlihat bahwa nilai AVE konstruk yang terdapat pada model penelitian ini di atas 0,5. Nilai AVE terendah 0.6452 pada konstruk kepuasan komunikasi. Data tersebut menunjukkan bahwa indikator yang digunakan dalam penelitian ini adalah valid atau telah memenuhi syarat discriminant validity.

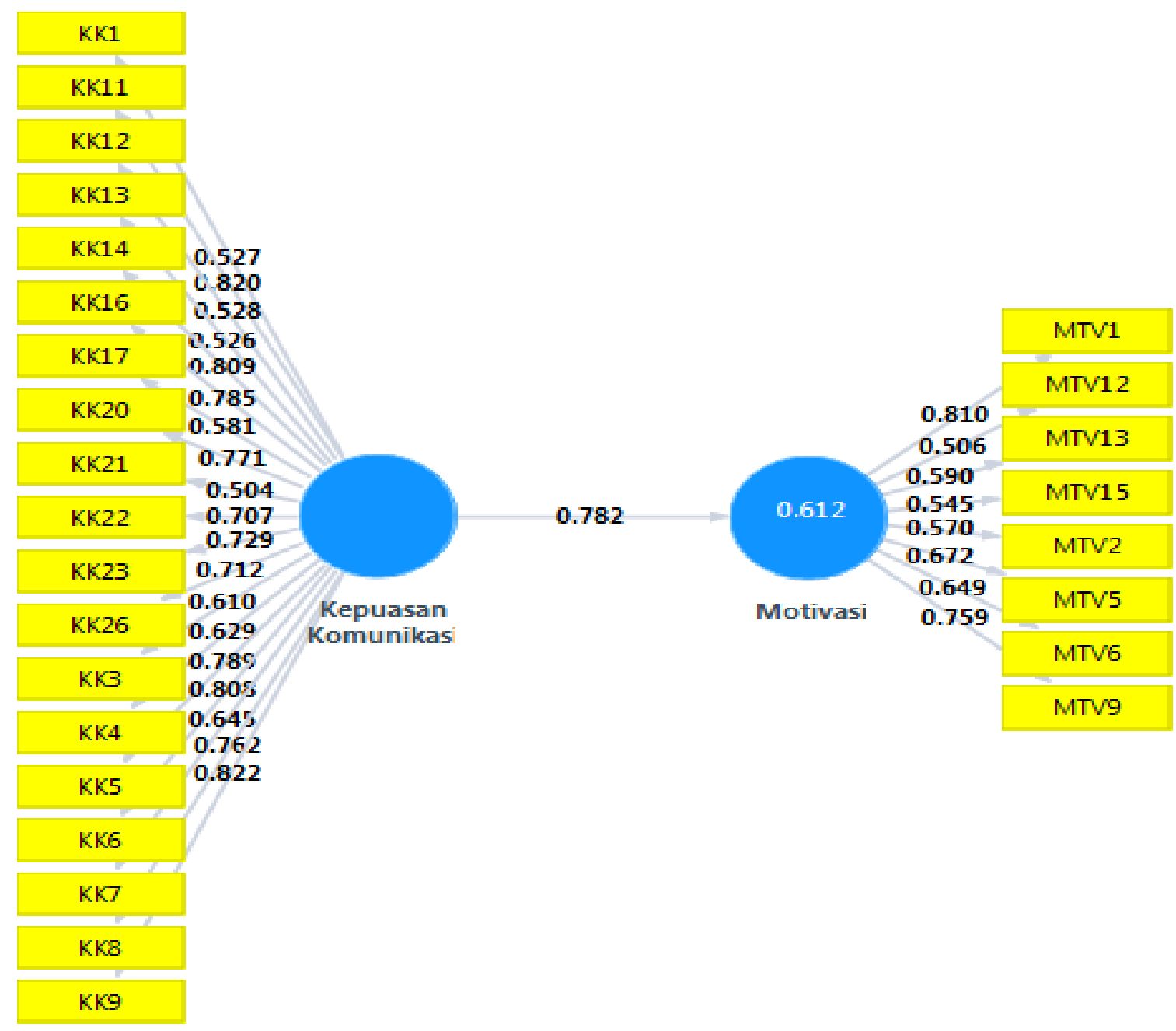

Gambar 2. Model PLS algorithm loading factor $>0.5$ loading factor tahap 2

Tabel 2. Nilai AVE, composite reliability, $R$ square dan cronbach's alpha

\begin{tabular}{lccccc}
\hline & AVE & $\begin{array}{c}\text { Composite } \\
\text { Reliability }\end{array}$ & R-Square & Cronbach's Alpha & Keterangan \\
\hline Kepuasan & & & & & Valid \\
komunikasi & 0,6963 & 0,9458 & 0 & 0,9476 & Valid \\
Motivasi kerja & 0,6452 & 0,8478 & 0,6121 & 0,8016 & \\
\hline
\end{tabular}

Sumber: Hasil Olahan Algorithm SmartPLS 2.0 (Data Diolah) 
Tabel 3. Nilai t-statistik (output bootstrapping)

$\begin{array}{lllll}\begin{array}{l}\text { Original Sample } \\ (\mathrm{O})\end{array} & \text { Sample Mean } & \text { Standard } & \text { Standard Error } & \mathrm{t} \text { Statistics } \\ & (\mathrm{M}) & \text { Deviation } & (\text { STERR }) & (|\mathrm{O} / \mathrm{STERR}|) \\ & & & \end{array}$

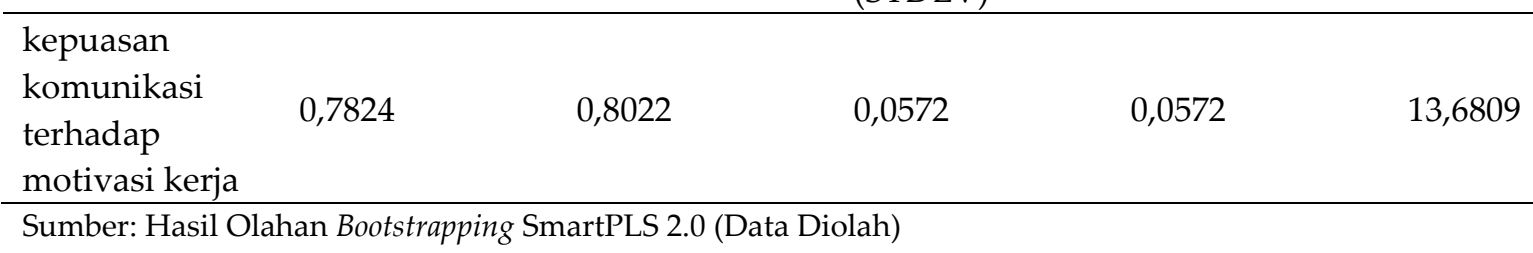

\section{Composite Reliability}

Uji reliabilitas dilakukan dengan melihat nilai composite reliability (reliabilitas komposit) dari blok indikator yang mengukur konstruk. Nilai batas yang diterima untuk tingkat reliabilitas komposit adalah $>0,6$, walaupun bukan merupakan standar absolut. Tabel 3 menunjukkan bahwa nilai composite reliability untuk semua konstruk di atas 0,6 yang menunjukkan bahwa semua konstruk pada model yang diestimasi memenuhi kriteria composite reliability. Nilai composite reliability yang terendah 0,8478 pada konstuk kepuasan komunikasi. Uji reliabilitas diperkuat dengan Cronbach's Alpha dimana output smartPLS versi 2.0 memberikan hasil sebagaimana tampak pada Tabel 2. Cronbach's Alpha yang disarankan adalah di atas 0,6. Pada Tabel 2 terlihat nilai Cronbach's Alpha untuk semua konstruk berada di atas 0,6. Nilai terendah adalah 0,8016 untuk konstruk motivasi kerja.

\section{Evaluasi Model Struktural (Inner Model)}

Setelah model yang diestimasi memenuhi kriteria outer model, berikutnya dilakukan pengujian goodness of fit untuk model struktural (inner model). Model struktural dievaluasi dengan menggunakan $R$-square untuk konstruk dependen. Dari Tabel 2 diketahui bahwa nilai $R$-square untuk motivasi kerja 0,6121 yang berarti bahwa variasi kepuasan komunikasi dapat menjelaskan variasi motivasi kerja 61,21\% dan selebihnya (38,79\%) dipengaruhi oleh peubah lain.

\section{Uji t-Statistik}

Pengujian hipotesis yang diajukan, dapat dilihat dari besarnya nilai t-statistik. Nyatanya parameter yang diestimasi memberikan informasi sangat berguna mengenai hubungan peubahpeubah penelitian. Batas untuk menolak dan menerima hipotesis yang diajukan adalah $\pm 1,96$, dimana apabila nilai $t$ berada pada rentang nilai -
1,96 dan 1,96 maka hipotesis akan ditolak atau dengan kata lain menerima Ho.

Berdasarkan hasil uji-t dengan taraf nyata 0,05 diketahui pengaruh kepuasan komunikasi terhadap motivasi adalah nyata $(13,68$ lebih besar dari t-tabel 1,96). Nilai original contoh (koefisien) 0,7 menunjukkan hubungan peubah kepuasan komunikasi dengan peubah motivasi adalah cukup kuat dan positif. Ini berarti Ho dalam penelitian ini ditolak dan $\mathrm{H}_{1}$ diterima yang menyatakan bahwa hubungan kepuasan komunikasi berpengaruh positif terhadap motivasi kerja diterima. Ini diartikan semakin baik kepuasan komunikasi karyawan di PD BPR Bank Pasar Bogor, maka motivasi kerja karyawan semakin tinggi.

\section{KESIMPULAN}

Kepuasan komunikasi berpengaruh nyata terhadap motivasi kerja karyawan, dimana 61,21\% dapat menjelaskan proses mencapai tujuan suatu organisasi dan berpengaruh produktivitas yang berimbas pada kinerja para karyawan sehingga kepuasan komunikasi sangat penting.

\section{DAFTAR PUSTAKA}

Aisah, S. 2011. Analisis Tingkat Kepuasan Komunikasi Karyawan dan Hubungannya dengan Produktivitas Kerja Karyawan pada Kantor Pusat PT Bukit Asam (persero), Tbk [Tesis]. Bogor (ID): Sekolah Pascasarjana, Institut Pertanian Bogor.

[BI] Bank Indonesia. 2015. Mengenal Bank Perkreditan Rakyat (BPR) [internet]. Terdapat pada http://www.bi.go.id/id/perbankan /edukasi/documents/ea49c9c9dd4546b98c35 21cf5ee25d12mengenalbpr.pdf (diunduh pada 12 Januari 2015).

Arifin, B. 2005.Pengaruh Faktor-Faktor Kepuasan Komunikasi Terhadap Kinerja Karyawan. 
Jurnal Studi Manajemen dan Organisasi, 2 (1):16-34.

Downs, C. W.\& Hazen, M. D. 1977. A factor analytic study of communication satisfaction. The Journal of Business Communication, 14 (3): 63-73.

Ekaningsih, A. S. 2013. Kepuasan Komunikasi sebagai Pemoderasi Pengaruh Kesesuaian Individu-Pekerjaan pada Kinerja dan Kepuasan Kerja Studi pada Karyawan di PT Perkebunan Nusantara IX (Persero) Unit PG Tasikmadu Karanganyar-Jawa Tengah. Jurnal Socioscientia Kopertis Wilayah XI Kalimantan, (5): 2 pp 191-198.

Ghozali, I. 2008. Structured Component Analysis (GSCA): Model Persamaan Struktural Berbasis Komponen. Cetakan pertama. Semarang (ID): Badan penerbit Universitas Diponegoro.

Ghozali, I. dan Latan, H. 2012. Partial Least Square Konsep, Teknik dan Aplikasi smartPLS 2.0M3 untuk Penetilian Empiris. Semarang (ID): Badan penerbit Universitas Diponegoro.

Khoerunnisa, D. 2013. Pengaruh Pengaruh Komunikasi Internal terhadap Motivasi Kerja karyawan di PT. PLN Distribusi Jawa Barat dan Banten Area Bandung [Skripsi]. Bandung: Universitas Pendidikan indonesia.

Mangkuprawira dan Hubies AV. 2007.Manajemen Mutu Sumber Daya Manusia. Bogor (ID): Ghalia Indonesia.

Muhammad, A. 2001. Komunikasi Organisasi. Edisi1 Cetakan 4. Jakarta: Bumi Aksara.

Primadini, I. 2012. Pengaruh Gaya Kepemimpinan Perempuan dan Tingkat Kepuasan Komunikasi Terhadap Kinerja Karyawan (Studi Pada Staf Administrasi Fakultas Ilmu Keperawatan Universitas Indonesia [Tesis]. Jakarta: Program Pascasarjana Universitas indonesia.

Pujiwati. 2012. Pengaruh Penerapan Sistem Penilaian Kinerja dan Sistem Pengembangan Karir Terhadap Komitmen Karyawan. Tesis.Departemen manajemen. Fakultas Ekonomi dan Manajemen Institut Pertanian Bogor. Bogor (ID).
Purwanto, S. B. 2013. Pengaruh Komunikasi, Motivasi dan Kepuasan Kerja terhadap Kinerja Karyawan (Studi pada Proyek Pondasi Tower di Timor Leste PT Cahaya Inspirasi Indonesia). Jurnal Aplikasi Manajemen, 11(1): 139-144.

Ramanathan R. 2003. An Introduction to Data Envelopment Analysis: A Tool for Performance Measurement. New Delhi (IN): Sage Publications.

Saepulloh.2004. Hubungan Iklim Komunikasi Organisasi Perusahaan dengan Motivasi Kerja Karyawan Serang Plant PT Cargill Indonesia [Tesis]. Bogor: Sekolah Program Pascasarjana, Institut Pertanian Bogor.

Steers, R. and Braunstein, D. 1976. A Behaviorally Based Measure of Manifest Needs in Work Settings. Journal of Vocational Behavior. Oct: pp254.

Tuzun, I. K. 2013.Organizational Levels of Analysis of Communication Satisfaction and Identification in Relation to Job Satisfaction.Journal of Economics, Business and Management,1(1):1-5.doi: 10.7763/JOEBM.2013.V1.1.

Umar, H. 2005. Riset Sumber Daya Manusia. Jakarta (ID): Gramedia Putaka Utama.

Untung, S. dan Agus, B. H. 2010. Pengaruh Kompetensi, Motivasi, Komunikasi, dan Kesejahteraan terhadap Kinerja Pegawai Dinas Pendidikan. Jurnal Manajemen Sumberdaya Manusia, 4(1):47 - 57.

Wahyuni, L. 2009. Pengaruh Komunikasi Organisasi terhadap Kinerja Karyawan Bagian Akuntansi dengan Komitmen Organisasi dan Tekanan Pekerjaan Sebagai Peubah Intervening (Studi Empiris pada Perusahaan Bumn di Provinsi Sumatera Barat) [Tesis]. Semarang: Program Pascasarjana, Universitas Diponegoro.

Wahyuntoro, N. 2012. Faktor-Faktor Penyebab Kredit Macet dan Teknik Pengendaliannya pada PT BPR Kurnia Sewon Bantul Periode 2007-2011 [Tesis].

Wiñska, J. 2010. Influence of Superiorsubordinate Communication on Employee Satisfaction. Journalof Positive Management, 1(1):110-124.

Yogyakarta: ProgramPascasarjana, Universitas Negeri Yogyakarta. 